\title{
Resistance Exercise, Electrical Muscle Stimulation, and Whole-Body Vibration in Older Adults: Systematic Review and Meta-Analysis of Randomized Controlled Trials
}

\author{
Nejc Šarabon ${ }^{1,2,3, * \mathbb{D}}$, Žiga Kozinc ${ }^{1,4}$, Stefan Löfler ${ }^{5,6}$ (D) and Christian Hofer ${ }^{7}$ \\ 1 Faculty of Health Sciences, University of Primorska, Polje 42, SI-6310 Izola, Slovenia; ziga.kozinc@fvz.upr.si \\ 2 InnoRenew CoE, Human Health Department, Livade 6, SI6310 Izola, Slovenia \\ 3 S2P, Science to practice, Ltd., Laboratory for Motor Control and Motor Behavior, \\ Tehnološki Park 19, SI-1000 Ljubljana, Slovenia \\ 4 Andrej Marušič Institute, University of Primorska, Muzejski Trg 2, SI-6000 Koper, Slovenia \\ 5 Physiko- \& Rheumatherapie, Institute for Physical Medicine and Rehabilitation, 3100 St. Pölten, Austria; \\ stefan.loefler@rehabilitationresearch.eu \\ 6 Centre of Active Ageing-Competence Centre for Health, Prevention and Active Ageing, \\ 3100 St. Pölten, Austria \\ 7 Ludwig Boltzmann Institute for Rehabilitation Research, 3100 St. Pölten, Austria; \\ christian.hofer@rehabilitationresearch.eu \\ * Correspondence: nejc.sarabon@fvz.upr.si; Tel.: +386-5-662-64-66
}

Received: 31 July 2020; Accepted: 7 September 2020; Published: 8 September 2020

\begin{abstract}
It has been shown that resistance exercise (RT) is one of the most effective approaches to counteract the physical and functional changes associated with aging. This systematic review with meta-analysis compared the effects of RT, whole-body vibration (WBV), and electrical muscle stimulation (EMS) on muscle strength, body composition, and functional performance in older adults. A thorough literature review was conducted, and the analyses were limited to randomized controlled trials. In total, 63 studies were included in the meta-analysis (48 RT, $11 \mathrm{WBV}$, and 4 EMS). The results showed that RT and WBV are comparably effective for improving muscle strength, while the effects of EMS remains debated. RT interventions also improved some outcome measures related to functional performance, as well as the cross-sectional area of the quadriceps. Muscle mass was not significantly affected by RT. A limitation of the review is the smaller number of WBV and particularly EMS studies. For this reason, the effects of WBV and EMS could not be comprehensively compared to the effect of RT for all outcome measures. For the moment, RT or combinations of RT and WBV or EMS, is probably the most reliable way to improve muscle strength and functional performance, while the best approach to increase muscle mass in older adults remains open to further studies.
\end{abstract}

Keywords: sarcopenia; falls; elderly; resistance exercise; vibration; electrical stimulation

\section{Introduction}

With rising life expectancy and the increasing proportion of older adults in the population [1,2], effective interventions that promote lifelong well-being and health are more needed than ever before. There is no doubt that performing physical exercise is one of the most effective ways for older adults to maintain functional independence, maintain physical abilities, and reduce the risk of various diseases and injuries [3-7]. One of the most notable changes associated with aging is sarcopenia, which is characterized by a loss of muscle mass and other subsequent changes, such as reduced muscle strength and impaired functional ability [8]. Together with nutritional interventions, resistance exercise training 
(RT) seems to be the most effective approach to prevent and treat sarcopenia [9-11]. Falls are also one of the major problems in the older adult population [12] and are thus given considerable attention in terms of prevention. It has been shown that the best way to prevent falls is by performing RT alone or in combination with other exercise types or other interventions $[13,14]$. Despite extensive research regarding the effects of resistance exercise on sarcopenia, fall risk, and general health of older adults, the recommendations for prescribing exercises in this population are still relatively vague and generic $[3,11,15]$. In contrast, previous studies have investigated several factors that are worth considering in order to maximize the effects of RT for older adults, such as intensity [16], speed of movement [17], and supervision of the training sessions [18]. Certain types of RT, such as speed-power training [19], are also increasingly being investigated as potentially superior to traditional resistance exercise.

Recent literature reviews have found numerous barriers, such as decreased physical ability, walking disability, lack of companionship, and lack of motivation, that are decreasing the participation of older adults in exercise programs [20,21]. For this reason, different methods to combat sarcopenia, prevent falls, and increase well-being in older adults should be considered as an alternative to RT. Recently, whole-body vibration (WBV) has been shown to improve postural balance [22] and muscle strength [23] and to reduce the likelihood of falls in older adults [24]. WBV is therefore a possible alternative to RT; however, direct comparisons between the effects of RT and WBV are lacking. Roelants et al., reported similar improvements in knee extension strength, jumping performance, and speed of movement after 12 and 24 weeks of RT and WBV interventions in older women [25]. Similarly, Bogaerts et al., showed comparable effects of WBV and RT on muscle mass and muscle strength in older men [26]. Another promising alternative to RT is electrical muscle stimulation (EMS) [27-31]. EMS has been shown to improve functional performance of aging muscles $[27,31]$ and to counteract muscle decline in old age [30]. Moreover, EMS has been appreciated as a convenient intervention for older adults with lower physical abilities or low motivation to exercise [32].

Although many positive effects of RT, WBV, and EMS in older adults have been consistently demonstrated, it is not entirely clear which interventions should be prioritized for the best health benefits. Moreover, studies often follow only a limited set of outcome measures, making comparisons between interventions difficult. Therefore, the objective of this work was to provide a comprehensive systematic review with meta-analysis of high-quality studies that assessed the effects of RT, WBV, or ES in older adults. To obtain a broad overview of these effects, we included studies that assessed various outcome measures, including muscle strength, body composition, and muscle morphology, and the outcomes of functional performance tests. In addition, the aim of this review was to examine the effects of several independent variables, pertaining to the intervention programs, such as (but not limited to) intervention duration, weekly frequency, volume, intensity, supervision, and compliance. We hypothesized that RT, WBV, and EMS will have similar effects on body composition, muscle strength, and functional performance.

\section{Materials and Methods}

\subsection{Inclusion Criteria}

Study inclusion criteria were structured according to PICOS tool [33]:

- Population (P): Male or female older adults. The criterion for inclusion was mean sample age $\geq$ 65.0 years. Patients with sarcopenia were included if they met this criterion (age $\geq 65.0$ years); however, sarcopenia was not an inclusion criterion.

- Intervention (I): RT, EMS, or WBW interventional programs of any duration. Studies exploring multimodal interventional programs (e.g., RT programs combined with stretching exercise) were excluded. 
- Comparisons (C): Control groups, receiving no intervention or placebo intervention. Groups that received cognitive training or other non-physical interventions were also accepted as control groups. Studies in which control groups received any type of exercise, vibration intervention, electrical stimulation, or nutritional supplementation were excluded.

- Outcomes (O): (a) Muscular strength or power, not limited to type of testing or body part; (b) body composition and muscle architecture (including body fat, fat free mass, muscle mass, regional muscle mass, skeletal muscle mass, cross-sectional muscle area, circumference measures, and sarcopenia index) and (c) functional mobility outcomes (timed up-and-go test, stepping tests, sit-stand tests, functional reach tests, etc.).

- Study design (S): Only randomized controlled trials (RCT) that included at least one intervention group (RT, EMS, or WBV) and control group.

\subsection{Search Strategy}

Multiple databases of scientific literature (PubMed, Cochrane Central Register of Controlled Trials, PEDro, and ScienceDirect) were searched in May 2020 without regard to the date of publication. For the databases that enable using Boolean search operators, we used the following combination of search key words: (sarcopenia OR muscle atrophy OR muscle wasting) and (training OR exercise OR vibration OR electrical stimulation OR electrostimulation OR magnetic stimulation OR vibration training OR physical therapy) and (strength OR power OR muscle mass OR muscle diameter) and (elderly OR older OR older adults OR ageing OR age-related). Otherwise, we used several reduced combinations of key words, including, but not limited to resistance exercise older adults, vibration training elderly, electrical stimulation elderly and older adults sarcopenia intervention. Additionally, reference lists of several review articles describing interventions for older adults were carefully scrutinized. Finally, we carefully reviewed reference lists of all articles that were already retrieved through the database search and were published within the last 4 years. The database search was performed independently by two authors (N.Š. and Ž.K.). Two reviewers (N.Š. and S.L.) also screened the titles and the abstracts independently. Potentially relevant articles were screened in full text, followed by additional screening for their eligibility by the additional reviewers.

\subsection{Data Extraction}

The data extraction was carried out independently by two authors (Ž.K. and C.H.) and disagreements were resolved through consultation with other authors. The extracted data included: (a) baseline and post-intervention means and standard deviations for all eligible outcome measures for interventional and control groups; (b) baseline demographics of participants (gender, age, body height, body mass, body mass index); (c) intervention characteristics (target body area (upper, lower or whole-body), duration of the intervention, number of sessions per week, volume (number of exercises, sets, and repetitions), breaks between exercises and sets, supervision, and progression of exercise difficulty). For studies examining RT, we also extracted the type of load used (bodyweight, machine, elastics, weights, etc.) and intensity as a percentage of 1-maximum repetition (1RM) or subjective measures, such as the Borg scale. For EMS studies, we further extracted the stimulation frequency and amplitude, the stimulated body parts, pulse shapes, and breaks between repetitions or sets. For WBV studies, we additionally extracted the amplitude and the frequency that was used during training. Data were carefully entered into Microsoft Excel 2016 (Microsoft, Redmond, WA, USA). If the data were presented in a graphical rather than tabular form, we used Adobe Illustrator Software (version CS5, Adobe Inc., San Jose, CA, USA) to accurately determine the means and standard deviations. In case of missing data, the corresponding author of the respective articles was contacted by e-mail. If no response was received after 21 days, the author was contacted again. If the author did not reply to the second inquiry, the data was considered irretrievable. 


\subsection{Assessment of Study Quality}

Two authors (Ž.K. and N.Š.) evaluated the quality of the studies using the PEDro tool [34], which assesses study quality based on a ten-level scale. Potential disagreements between ratings were resolved by consulting the other authors. Studies scoring from 9-10 were considered as "excellent," 6-8 as "good," $4-5$ as "fair," and less than 4 as "poor" quality. The PEDro scale was chosen because it was developed specifically to assess the quality of randomized controlled trial studies evaluating physical therapist interventions [34].

\subsection{Data Analysis and Synthesis}

The main data analyses were carried out in Review Manager (Version 5.3, Copenhagen: The Nordic Cochrane Centre, The Cochrane Collaboration, 2014, London, UK). Before the results were entered into the meta-analytical model, the pre-post differences and pooled standard deviations were calculated according to the following formula $\mathrm{SD}=\sqrt{ }\left[\left(\mathrm{SD}_{\text {pre }}{ }^{2}+\mathrm{SD}_{\text {post }}{ }^{2}\right)-\left(2 \times \mathrm{r} \times \mathrm{SD}_{\text {pre }} \times \mathrm{SD}_{\text {post }}\right)\right.$. The correction value $(\mathrm{r})$, which represents the pre-test-post-test correlation of outcome measures, was conservatively set at 0.75 . It should be noted that a change in the correction value in the range between 0.5 and 0.9 had little effect on the pooled SD and would not change the outcomes of the meta-analyses. For the meta-analyses, the inverse variance method for continuous outcomes with a random-effects model was used. The pooled effect sizes were expressed as mean difference (MD) where possible, which allows the effect size to be expressed in units of measurement. Where this was not possible due to the heterogeneity of the outcome variables (e.g., muscle strength reported in $\mathrm{kg}, \mathrm{N}, \mathrm{Nm}, \mathrm{N} / \mathrm{kg}$, and $\mathrm{Nm} / \mathrm{kg}$ ), the effect sizes were expressed as standardized mean difference (SMD). For MD and SMD, the respective $95 \%$ confidence intervals were also calculated and reported.

Basic analysis compared the effects of the RT, EMS, and WBV interventions. Further subgroup analyses were conducted where possible (depending on the number of studies reporting a given outcome) based on several independent variables, related to the characteristics of the interventions (e.g., weekly number of sessions). Some outcomes did not appear in EMS and WBV studies and were thereby only analyzed in view of RT studies. Statistical heterogeneity among studies was determined by calculating the I 2 statistics. According to Cochrane guidelines, the I 2 statistics of $0 \%$ to $40 \%$ might not be important, $30 \%$ to $60 \%$ may represent moderate heterogeneity, 50\% to $90 \%$ may represent substantial heterogeneity, and $75 \%$ to $100 \%$ indicates considerable heterogeneity [35]. The threshold for statistical significance was set at $p \leq 0.05$ for the main effect size and the subgroup difference tests.

Sensitivity analysis was performed when deemed necessary i.e., by examining the effect of exclusion of certain studies from the analyses (e.g., studies that could have included subsets of previous studies, studies with very low compliance, studies that did not report intensity, studies with and without elderly with sarcopenia, etc.). The sensitivity analyses showed no or very little effect on the main results (SMD changes $=0.01-0.10$ ), except where noted and reported in the results.

\section{Results}

\subsection{Summary of Search Results}

The results of the search steps are summarized in Figure 1. The search resulted in 64 studies in total, 48 of which included RT interventions (55 intervention groups in total), 12 included WBV interventions (14 intervention groups in total) and 4 included EMS interventions (4 intervention groups in total). A table encompassing all the details regarding the participants, interventions and outcomes of individual studies is included in Supplementary data 1. 


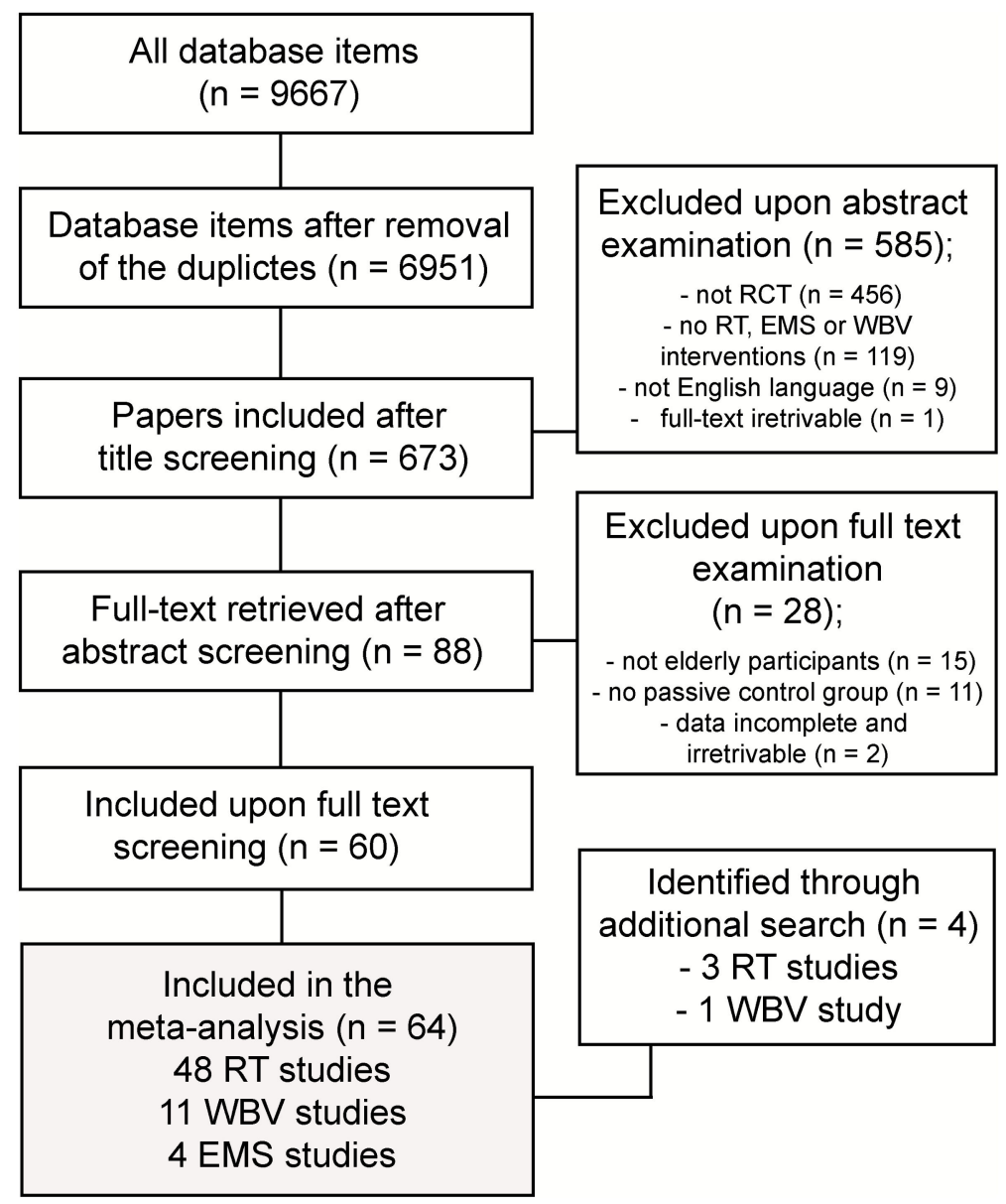

Figure 1. Summary of search results. RT—resistance training; WBV—whole-body vibration; EMS—electrical muscle stimulation.

\subsection{Study Quality Assessment}

The PEDro scale scores indicated overall fair to good quality of the RT studies (mean $=5.25$ \pm 1.26 ; median $=5.0$; range $=2-8)$ and WBV studies (mean $=5.41 \pm 1.24$; median $=5.5$; range $=$ $4-7$ ). Studies exploring EMS were all rated as good (mean $=6.52 \pm 1.03$; median $=6.0$; range $=6-8$ ). The most common items that almost all studies failed to satisfy were blinding of the subjects, therapists and assessors.

\subsection{Participant Data and Intervention Characteristics}

In total, there were 2017 participants (1158 in intervention groups and 1026 in control groups) in the RT studies, 606 in WBV studies (325 in intervention groups and 284 in control groups), and 192 in the EMS studies (99 in intervention groups and 93 in control groups). Across all studies, the pooled participant age was $73.5 \pm 4.8$ years (range of means: 65-92 years), the pooled participant body mass was $65.8 \pm 10.33 \mathrm{~kg}$ (range of means: $40.5-101.8 \mathrm{~kg}$ ), and the pooled body mass index was $26.39 \pm$ $3.77 \mathrm{~kg} / \mathrm{m}^{2}$ (range of means: $18.8-36.7 \mathrm{~kg} / \mathrm{m}^{2}$ ). In total, 36 included participants of both genders, 24 studies included only females, and 4 studies included only males. In 16 RT studies, sarcopenia was listed as an inclusion criterion. In 47 studies, the interventions were supervised, while the interventions in the remaining studies were not supervised $(n=9)$ or the information regarding the supervision was missing $(n=7)$. The most typical duration of the interventions was 12 weeks $(n=28)$, while 12 interventions were shorter (4 interventions lasted 5-6 weeks, and 8 interventions lasted 8-11 weeks) and 23 interventions were longer (12 interventions lasted 13-24 weeks, and 11 interventions lasted 25 weeks or more). Most interventions included either $2(n=23)$ or $3(n=32)$ sessions per week, while 5 
interventions were performed once per week and 3 interventions were performed $4-5$ times per week. Only $4 \mathrm{WBV}$ and 19 RT studies reported adherence to the intervention program, with mean values of $90 \pm 3 \%$ and $84 \pm 9 \%$, respectively.

Across the RT studies, 14 intervention programs used machines, 6 used free weights, 5 used elastic resistance, 4 implemented bodyweight exercises, 1 used weighted tai-chi exercises, and 1 used isoinertial exercises on a flywheel device. The remaining 17 studies used mixed approaches ( 5 combined bodyweight and elastic exercise, 2 combined free weights and bodyweight exercises, 3 combined free weights and machines, and 7 used more three or four types of load). RT interventions included either full body workout $(n=32)$ or focused on the lower limb muscles $(n=16)$, while no interventions focused only on the trunk or the upper limbs. Most often $(n=29)$, the intervention included a combination of single-joint and multi-joint exercises; however, some interventions included predominantly single-joint $(n=12)$ or multi-joint $(n=7)$ exercises. The volume of exercise varied substantially between studies, with the number of exercises ranging from 1 to 12 (mean: $5.9 \pm 2.9$ ), the number of sets ranging from 1 to 5 (mean: $2.7 \pm 0.8$ ), and number of repetitions within sets ranging from 7 to 25 (mean: $11.0 \pm 3.5$ ). Intensity was set as percentage of 1-repetition-maximum in 27 studies (mean: $66.2 \pm 15.3 \%$; range: $20-80 \%$ ) or using the 6-20 Borg scale for assessment of the rate of perceived exertion in 10 studies (all studies used 13 as the target value). One study determined the intensity as percentage of maximal heart rate (set between 60 and $80 \%$ ). The remaining 12 studies did not report the intensity of the exercise. Breaks between sets were reported in 11 studies and ranged from $30 \mathrm{~s}$ to $150 \mathrm{~s}$ (mean: $100 \pm 45 \mathrm{~s}$ ). Breaks between exercises were only reported in 5 studies (range: 90-180 s).

In WBV studies, the number of exercises ranged from 1 to 9 (mean: $3.8 \pm 3.1$ ) and the number of sets ranged from 1 to 10 (mean: $3.5 \pm 2.7$ ). With the exception of 1 study, which used highly varying vibration frequency $(27-114 \mathrm{~Hz}$ ), the frequencies used ranged from 20 to $60 \mathrm{~Hz}$ (mean: $35.7 \pm 10.1 \mathrm{~Hz}$ ). The amplitude of the vibration ranged from 2 to $6 \mathrm{~mm}$ (mean: $3.8 \pm 1.4 \mathrm{~mm}$ ). Breaks between sets ranged from 30 to $180 \mathrm{~s}$ (mean: $75 \pm 53.8 \mathrm{~s}$ ).

Finally, 3 EMS studies targeted full body (all used stimulation frequency of $85 \mathrm{~Hz}$, impulse width at $350 \mu \mathrm{s}$, moderate intensity (subjectively determined) and lasted $20 \mathrm{~min}$ per session), while 1 study stimulated only the lower limbs (frequency: $100 \mathrm{~Hz}$; amplitude: 40-120 mA; impulse width: $400 \mu \mathrm{s}$ ).

\subsection{Effects of RT and WBV on Muscle Strength}

Knee extension strength was by far the most common outcome across studies and was reported in 2 EMS studies with 2 intervention groups [36,37], 6 WBW studies with 8 intervention groups [25,26,38-42], and 26 RT studies with 29 intervention groups [25,43-67]. In total, 5 studies measured isokinetic strength ( 1 study at $30^{\circ} / \mathrm{s}, 3$ studies at $60^{\circ} / \mathrm{s}$ and 1 study sat $90^{\circ} / \mathrm{s}$ ), and the rest measured isometric strength. Figure 2 displays the main analysis, comparing the effect of WBV, RT, and EMS on knee strength. Due to substantial discrepancy between the studies in terms of units of reporting, only the SMD could be computed.

There was a statistically significant increase in knee extension strength in the intervention groups across all studies compared to control groups (SMD $\left.=1.12(0.86-1.37) ; p<0.001 ; \mathrm{I}^{2}=83 \%\right)$. Both WBV interventions $\left(\mathrm{SMD}=0.97(0.34-1.59) ; p=0.00 ; \mathrm{I}^{2}=90 \%\right)$ and RT interventions (SMD = $1.24(0.96-1.52)$; $\left.p<0.001 ; \mathrm{I}^{2}=79 \%\right)$ improved knee extension strength, while EMS did not (SMD $=-0.08(-1.08-0.91)$; $\left.p=0.88 ; \mathrm{I}^{2}=81 \%\right)$. RT appeared superior to WBV; however, the difference between intervention types was not statistically significant $(p=0.32)$. For WBV, the subgroup analysis was performed for intervention duration and indicated that interventions longer than 24 weeks have a higher effect (SMD $=1.61(0.35-2.87)$ than interventions lasting up to 12 weeks $(\mathrm{SMD}=0.55(0.21-0.88)$ or interventions lasting 13-24 weeks (SMD $=0.55(-0.29-1.40)$ ), although the subgroup test showed that this difference was not statistically significant $(p=0.28)$. Within the RT studies, most interventions lasted 12 weeks (17/26 studies). Subgroup analyses showed no effect of intervention duration on knee strength increases (SMD $=0.94-1.26$ across subgroups). The effect of RT was the highest in studies with participants aged $>80$ years $(\mathrm{SMD}=1.76(1.01-2.52)$, lower in the $<70$-year-old subgroup $(\mathrm{SMD}=$ 
$1.17(0.73-1.61)$ and the lowest in the 70-80-year-old subgroup (SMD $=0.95(0.65-1.25))(p=0.14$ for subgroup differences). The effect was comparable in studies using predominantly single-joint (SMD $=1.38(0.70-2.07)$, predominantly multi-joint $(\mathrm{SMD}=1.12(0.33-1.90))$, or a combination of singleand multi-joint exercises (SMD $=1.27(0.91-1.62))(p=0.88$ for subgroup differences). No differences between studies were found $(p=0.68)$ based on the type of resistance, though there was a trend for higher effect of interventions based on machine training (SMD $=1.36(0.97-1.75)$ ) and free weights $(\mathrm{SMD}=1.33(0.37-2.29))$ compared to elastic resistance $(\mathrm{SMD}=0.91(0.20-1.63))$ and approaches that combined multiple types of resistance (SMD $=0.98(0.49-1.47))$. Finally, studies were grouped according to number of sessions per week and no differences were found between interventions performed $\leq 2$ times per week $(\mathrm{SMD}=1.30(0.92-1.68))$ and $\geq 3$ times per week $(\mathrm{SMD}=1.15(0.75-1.55))$ ( $p=0.59$ for subgroup differences).

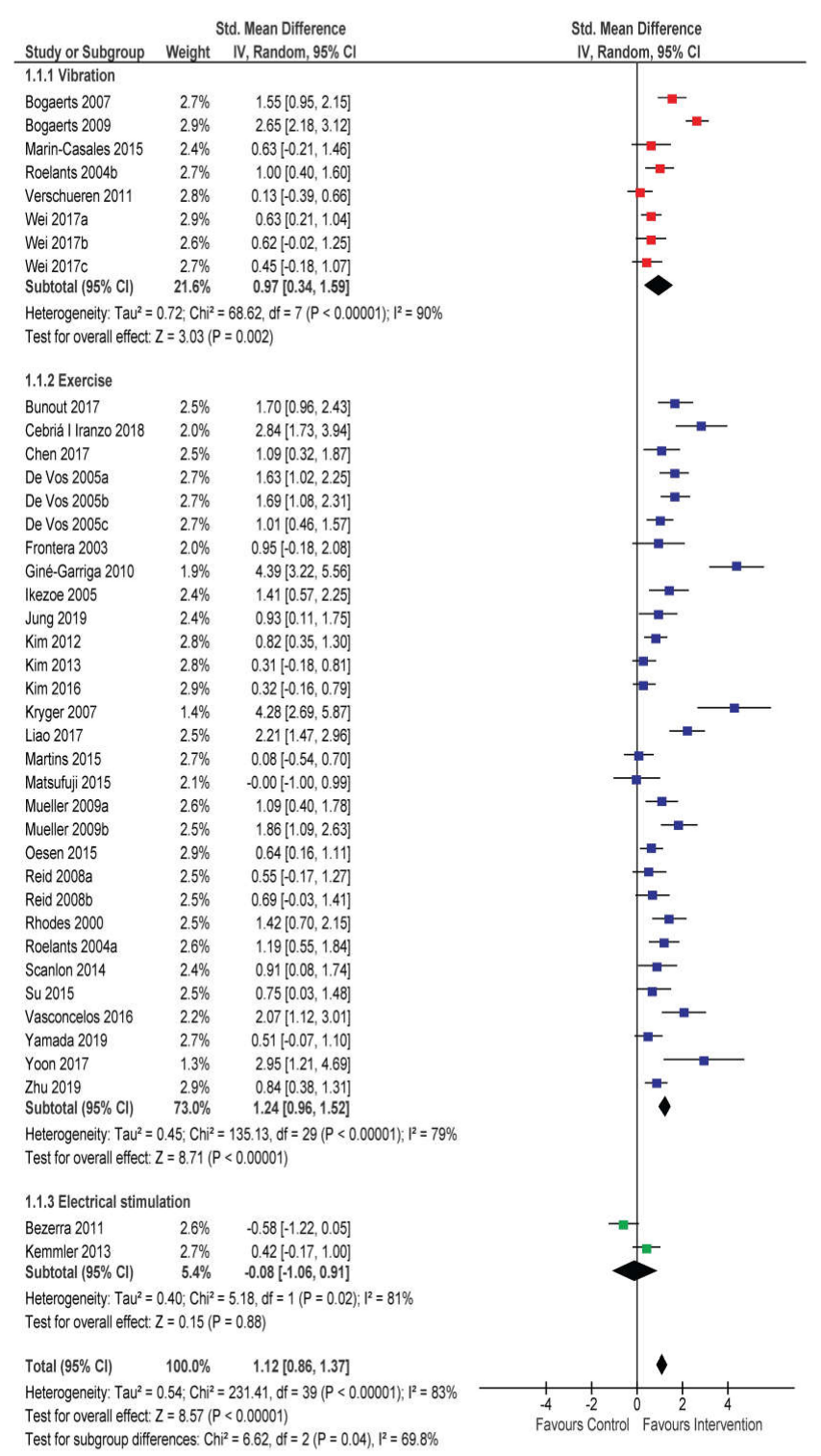

Figure 2. Effects of whole-body vibration, resistance exercise, and electrical muscle stimulation interventions on knee extension strength.

Sensitivity analysis was performed to examine the effect of certain concerns regarding the studies. Since it was not entirely clear if Bogaerts et al. (2007 and 2009, see Figure 2, top section) reported the data for entirely different sample in the two studies, we excluded the study with smaller sample size. The pooled effect of WBV was decreased from 0.97 to 0.88 ; however, it was still statistically significant 
$(p=0.01)$. Furthermore, $4 \mathrm{WBV}$ studies included in this analysis involved some component (lunges, squats) of RT. Therefore, it is unclear if this RT component contributed to the overall improvements. Removing these studies from the analysis yields a lower overall effect (SMD $=0.59(0.30-0.87)$, which is statistically still significant $(p=0.03)$; however, with this reduction in studies, the subgroup analyses indicate statistically significant difference $(p=0.001)$ between RT and WBV, indicating the superiority of RT compared to WBV without any RT components. Additionally, we repeated the analysis with exclusion of RT studies on sarcopenia patients (SMD increased from 1.24 to 1.34) and vice versa (SMD dropped to 1.01). Therefore, a slight tendency for larger effect in healthy older adults was indicated. A final sensitivity analysis was performed for type of measurement. Removing the studies that measured isokinetic strength increased the main effect slightly (from 1.24 to 1.33). However, the studies with isokinetic measurements also had large and statistically significant pooled effect (SMD $=0.88 ; p<$ 0.001), which suggest isokinetic and isometric strength both substantially increased with RT.

Leg press strength was reported in 5 RT studies (8 interventional groups) $[46,60,61,68,69]$. There was a statistically significant increase in intervention groups across studies (SMD $=1.45(0.85-2.06) ; p<$ $0.001 ; \mathrm{I}^{2}=83 \%$ ) (Figure 3). Interventions performed 3 times per week tended to have a larger effect $(\mathrm{SMD}=1.98(0.50-3.45))$ than interventions performed 2 times per week $(\mathrm{SMD}=1.12(0.78-1.47))$, but the subgroup difference was not statistically significant $(p=0.27$ for subgroup differences). Two RT studies reported back extensor strength $[45,70]$ and showed a statistically significant increase (MD = $7.97 \mathrm{~kg}(3.07-12.88 \mathrm{~kg}) ; p<0.001 ; \mathrm{I}^{2}=0.0 \%$ ) (Figure 3). Three RT studies [71-73] reported a composite score for strength (i.e., sum of several strength tasks). There was a statistically significant improvement in intervention groups (SMD = $3.55(2.28-4.83) ; p<0.001 ; \mathrm{I}^{2}=90 \%$ ) (Figure 3). Grip strength was reported in $19 \mathrm{RT}$ studies $[44,45,49,52,53,55,56,59,61,65,67,69,70,74-79]$. There was a mean increase of $1.48 \mathrm{~kg}(0.26-2-23 \mathrm{~kg} ; p<0.001)$ across studies with pre-post mean differences ranging from -1.00 to $5.70 \mathrm{~kg}$.

\subsection{Effects of RT on Body Composition}

Muscle mass was reported in 7 RT studies (8 intervention groups) $[45,52,70,71,74,78,80]$. Compared to control groups, there was not a statistically significant increase in muscles mass in intervention groups across studies ( $\mathrm{MD}=0.60 \mathrm{~kg}(-0.18-1.37 \mathrm{~kg}) ; p=0.13 ; \mathrm{I}^{2}=83 \%$ ) (Figure 4). There were no differences between interventions performed 2 times a week (MD $=0.60 \mathrm{~kg}(-1.01-2.22$ $\mathrm{kg})$ ) and 3 times a week $(\mathrm{MD}=0.68 \mathrm{~kg}(0.23-1.14 \mathrm{~kg}))(p=0.93$ for subgroup differences). Appendicular muscle mass was reported in 7 RT studies [51-53,65,70,80-82]. The pooled effect showed no change after RT interventions compared to control groups (MD $=0.01 \mathrm{~kg}(-0.26-0.28 \mathrm{~kg}) ; p=0.92 ; \mathrm{I}^{2}=8 \%$ ) (Figure 4). Lower-limb muscle mass was reported in 8 RT studies [51-53,55,56,67,80,82], with an overall small and statistically non-significant increase (MD $\left.=0.18 \mathrm{~kg}(-0.11-0.47 \mathrm{~kg}) ; p=0.22 ; \mathrm{I}^{2}=45 \%\right)$ (Figure 4). No statistically significant differences were shown between interventions performed 3 times per week (MD $=0.55 \mathrm{~kg}(-0.44-1.55 \mathrm{~kg}))$ compared to interventions performed 2 times per week (MD $=0.10 \mathrm{~kg}(-0.10-0.31 \mathrm{~kg}))(p=0.39$ for subgroup differences). Upper limb muscle mass was reported in 5 RT studies $[53,56,67,80,82]$, and the pooled effect was negligible (MD $=0.01 \mathrm{~kg}(-0.11-0.13 \mathrm{~kg}) ; p=$ $0.84 ; I^{2}=0 \%$ ) (Figure 4 ). 


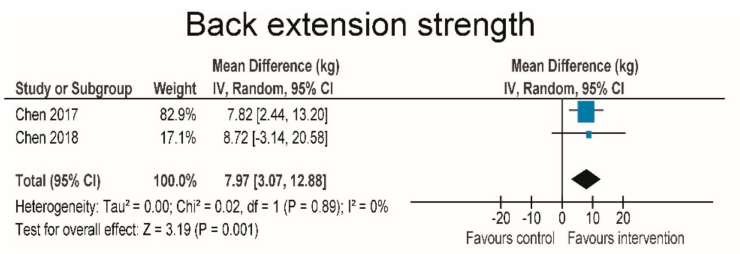

Leg press strength

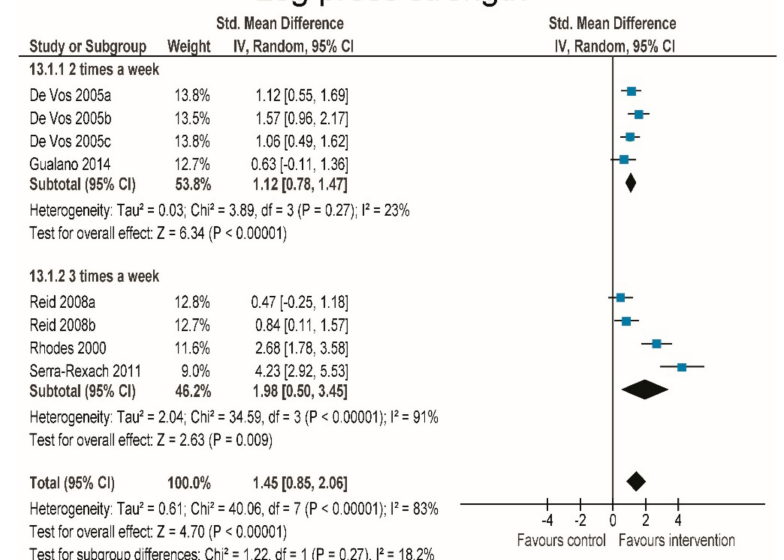

Test for

\section{Composite strength scores}

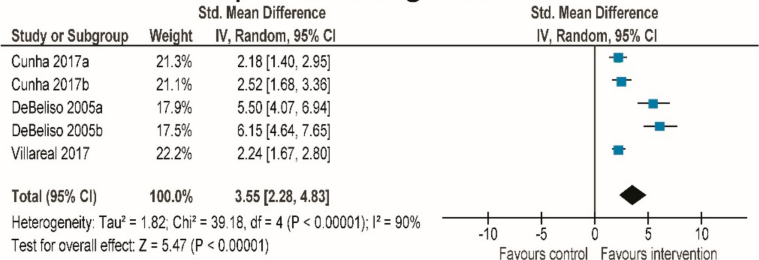

Figure 3. Effect of resistance exercise interventions on back extension, leg press, and composite strength scores.
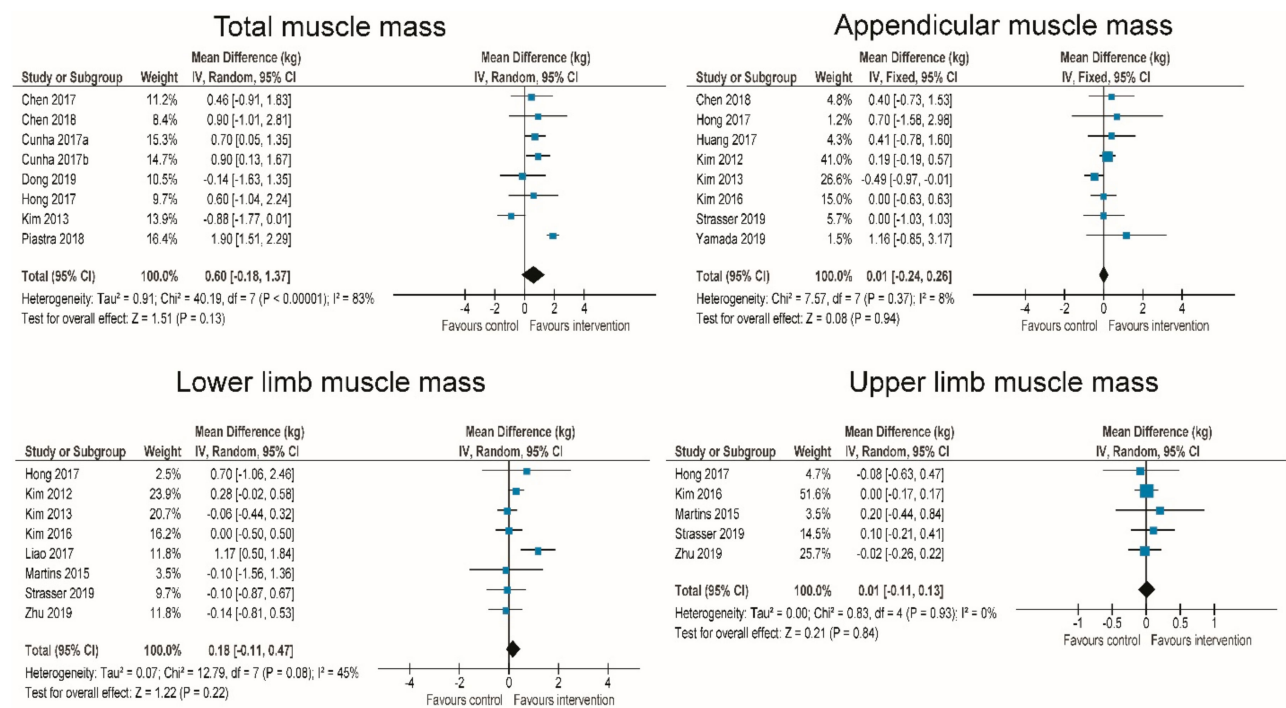

Figure 4. Effect of resistance exercise interventions on muscle mass.

Fat-free mass was recorded in 2 WBV [39,83], 7 RT [55,62,73-76,81], and 1 EMS studies [84], with a very small and statistically non-significant reduction across studies ( $\mathrm{MD}=-0.27 \mathrm{~kg}(-0.84-0.31 \mathrm{~kg})$; $\left.p=0.46 ; \mathrm{I}^{2}=0 \%\right)$. The pooled effect of the two WBV studies showed a slight increase $(\mathrm{MD}=0.53$ $\mathrm{kg}(-1.75-2.81 \mathrm{~kg}) ; p=0.15)$, as did one EMS study $(\mathrm{MD}=0.61 \mathrm{~kg}(-0.81-2.03 \mathrm{~kg}) ; p=0.40)$, while there was a small and statistically non-significant decrease across RT interventions $(\mathrm{MD}=-0.60 \mathrm{~kg}$ 
$(-1.28-0.09 \mathrm{~kg}) ; p=0.09)$. The differences between WBV, RT, and EMS were not statistically significant $(p=0.25)$.

Body fat mass was reported in 2 WBV [39,41] and 14 RT (16 intervention groups) studies $[45,50,53,55,58,62,70,71,73,74,76,80,81,85]$, with a statistically significant decrease overall (SMD $\left.=-0.65(-1.09-0.21) ; p<0.001 ; \mathrm{I}^{2}=86 \%\right)$. For the purposes of MD calculation, three studies $(4$ intervention groups) $[45,58,74]$ that reported body mass in $\mathrm{kg}$ instead of the percentage of body weight were removed and the analysis was repeated. SMD slightly increased (SMD $=-0.74$ ) and MD calculation showed a mean reduction of body fat mass percentage of $-1.99 \%(-3.75--0.22 \%)$.

Nine RT studies $[44,50,67,70,74,77,78,82]$ and one EMS study [86] also reported the sarcopenia index (sometimes termed skeletal muscle index) (Figure 5). Mainly (7 studies), the index was computed as the ratio of appendicular skeletal muscle mass and the square body height. However, since two studies did not report the exact calculation of the index, we opted for SMD in order analyses to be conservative. There was a moderate, but statistically non-significant improvement across all studies $\left(\mathrm{SMD}=0.65(-0.02-1.32) ; p=0.06 ; \mathrm{I}^{2}=90 \%\right)$. Subgroup analyses favored RT interventions, performed 2 times weekly $(p=0.008)$; this is being heavily influenced by one RT study that showed substantial improvement $(\mathrm{SMD}=3.44)$. Most of the studies showed very small negative or very small positive effects, while the pooled effect was heavily influenced by the aforementioned study. Furthermore, 3 WBV studies $[42,87,88]$ (5 intervention groups) and 3 RT studies $[47,62,66]$ reported the quadriceps muscle (or individual heads of quadriceps muscle) cross-sectional area. In order to obtain a sufficient number of studies for meaningful comparison, these results were compared together and expressed as SMD. Overall, there was a statistically significant effect of interventions (SMD $=0.29(0.03-0.55)$; $p=0.03 ; \mathrm{I}^{2}=0 \%$ ) (Figure 5). Subgroup differences showed no differences between RT (SMD $=0.61$ $(0.04-1.18)$ ) and WBV (SMD $=0.20(-0.09-0.49)(p=0.21$ for subgroup differences). For the RT studies (all reported the cross-sectional area for the full quadriceps muscle), the MD was $1.80(0.51-3.09) \mathrm{cm}^{2}$. One RT study [57] reported thigh circumference, with no effect of the intervention (MD $=-0.10 \mathrm{~cm}$ $(-2.55-2.35 \mathrm{~cm}) ; p=0.94 ; \mathrm{I}^{2}$ not applicable).

Two RT studies $[58,89]$ reported the percentage of type I fibers, with small and statistically non-significant pooled effect $\left(\mathrm{MD}=0.14 \%(-1.38-1.66 \%) ; p=0.86 ; \mathrm{I}^{2}=0 \%\right)$. The same two studies reported the percentage of type IIa fibers, showing slight but statistical non-significant increase (MD = $\left.1.03 \%(-0.43-2.48 \%) ; p=0.17 ; \mathrm{I}^{2}=11 \%\right)$. Finally, one RT study [58] reported a statistically significant increase in the percentage of type IIx fibers (MD $=2.42 \%(1.96-2.88) ; p<0.001 ; \mathrm{I}^{2}$ not applicable).

\subsection{Effects of RT and WBV on Body Functional Performance}

The results on functional performance are summarized in Figure 6. The timed up-and-go test was performed in 2 WBV $[87,88]$ and 6 RT studies $[52,55,69,75,90]$. Overall, there were no differences between intervention and control groups across all studies ( $\mathrm{MD}=-0.12 \mathrm{~s}(-1.36-1.12 \mathrm{~s}) ; p=0.85 ; \mathrm{I}^{2}=93 \%$ ). There were also no differences between the WBV and RT (MD $=0.20$ and $-0.08 \mathrm{~s}$, respectively; $p=0.89$ for subgroup differences). The 30-s sit-stand test was performed in 6 RT studies $[55,59,68,76,80,85]$, with an overall improvement of 2.68 repetitions (1.90-3.47 repetitions, $\left.p<0.001 ; \mathrm{I}^{2}=0.50 \%\right)$. There was no difference between interventions performed 2 times per week ( $\mathrm{MD}=2.85(1.16-4.54$ repetitions)) and 3 times per week ( $\mathrm{MD}=2.73(2.07-3.39$ repetitions) $)(p=0.90$ for subgroup differences). The 5-repetition sit-stand test was recorded in 4 RT studies $[65,67,75,76]$, and there was a significant improvement (i.e., decreased time to complete the test) across all studies ( $\mathrm{MD}=-2.36 \mathrm{~s}(-3.9--0.82 \mathrm{~s}) ; p=0.003 ; \mathrm{I}^{2}=83 \%$ ). 


\section{Sarcopenia index}

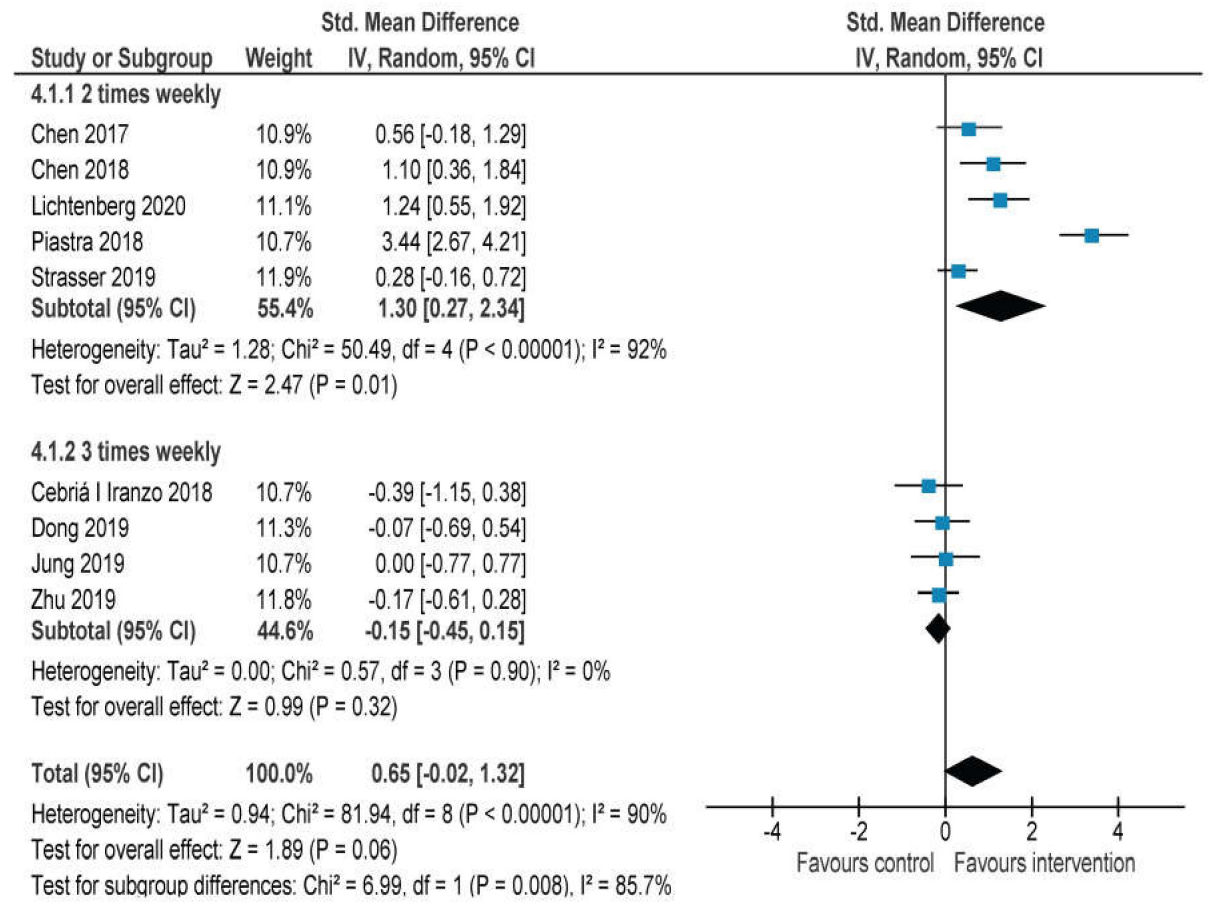

\section{Quadriceps cross-sectional area}

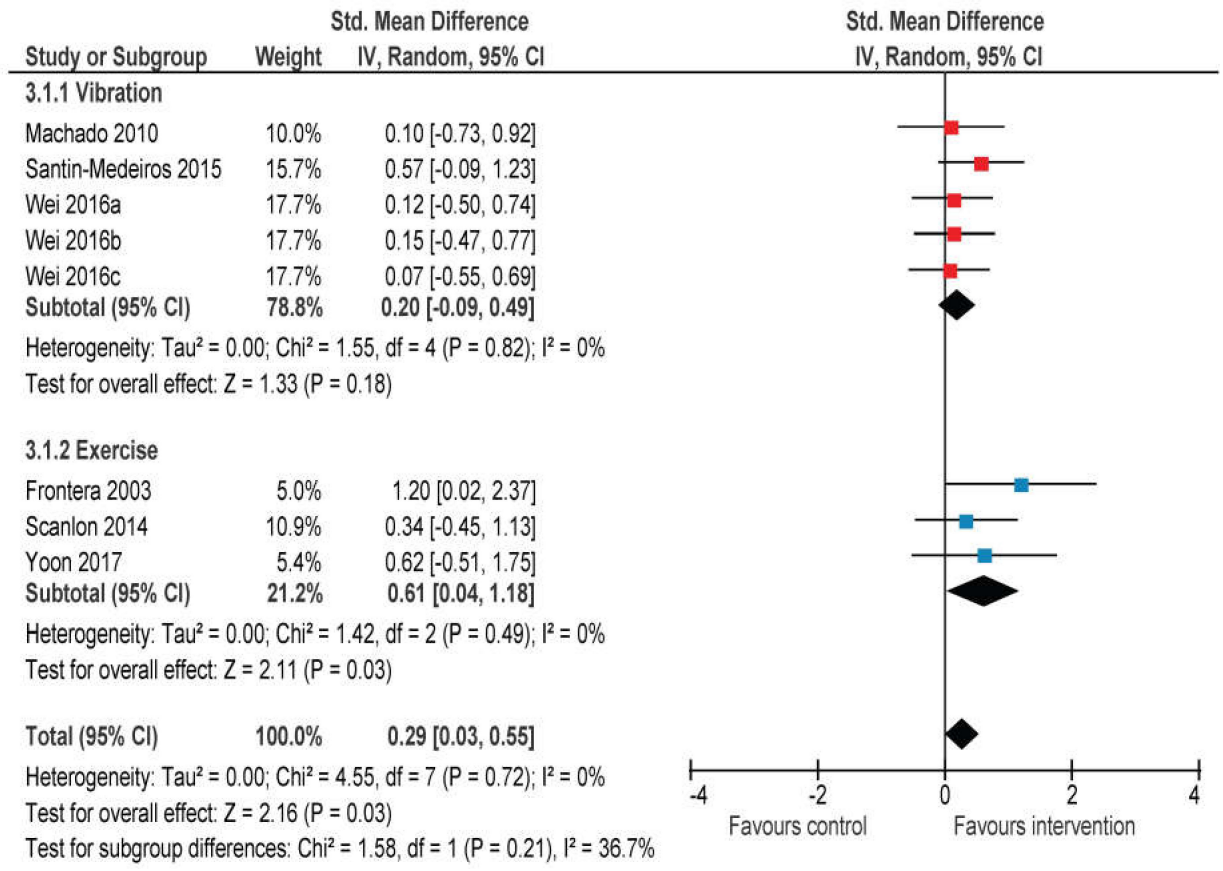

Figure 5. Effects of whole-body vibration and resistance exercise on sarcopenia index and quadriceps cross-sectional area. 


\section{Timed-up-and-go test}

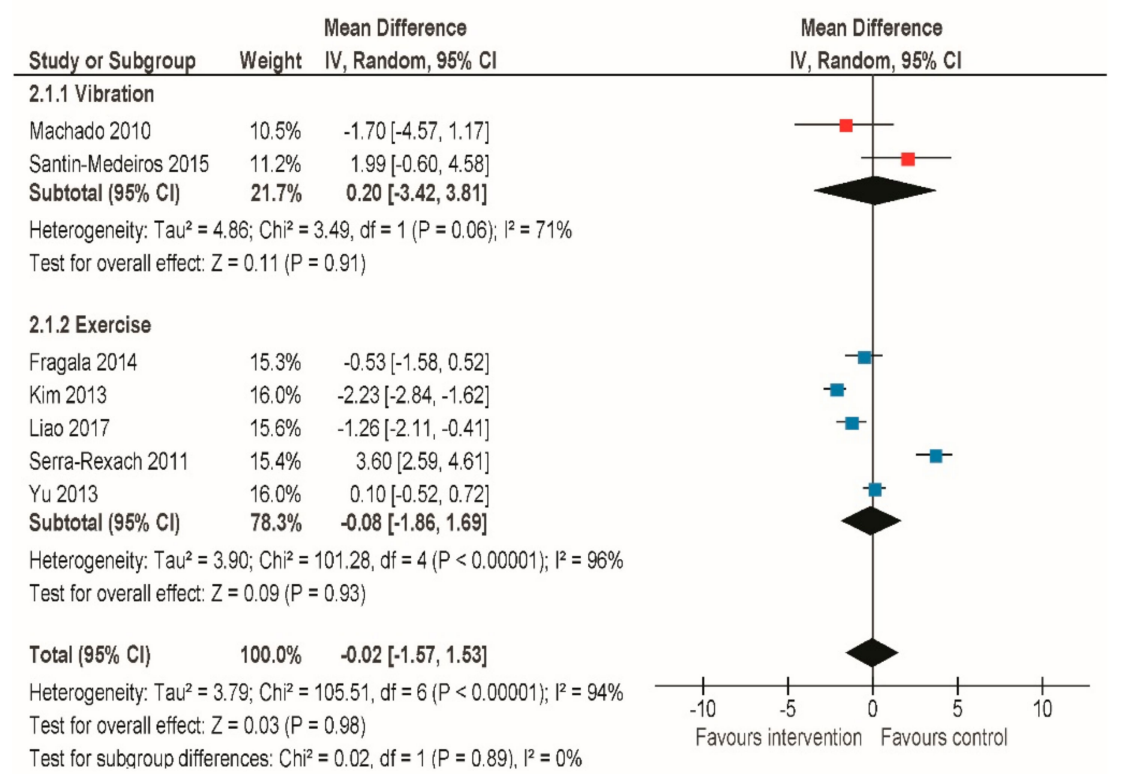

\section{0-second sit-stand test}

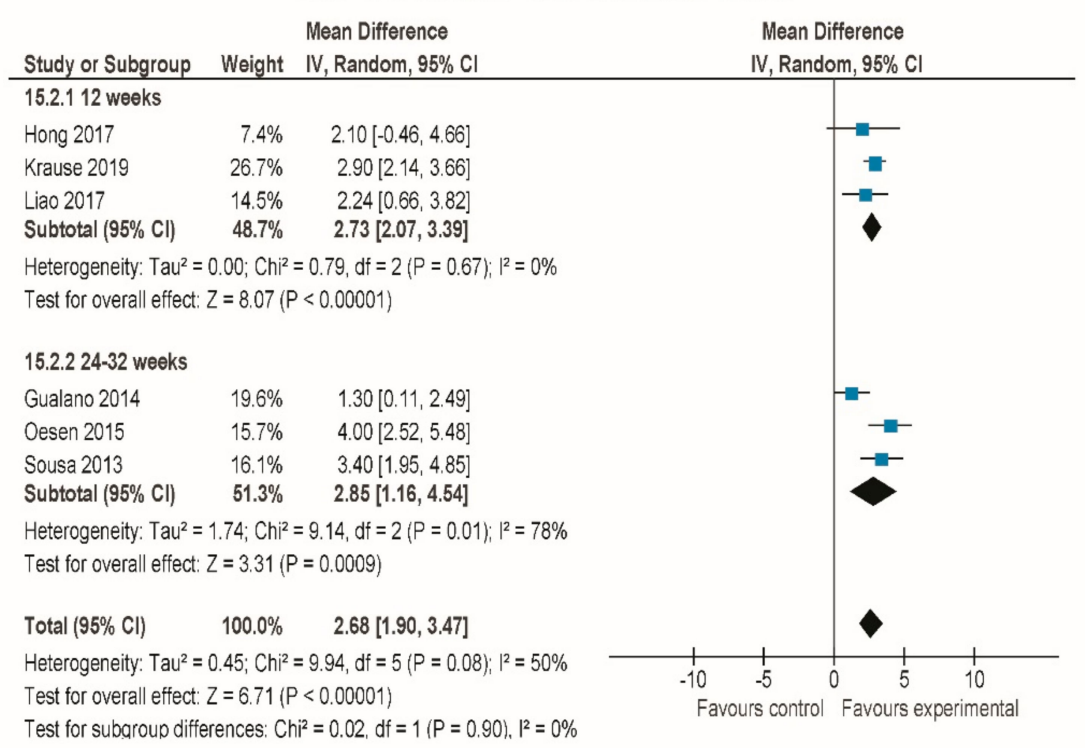

\section{5-repetition sit-stand test}

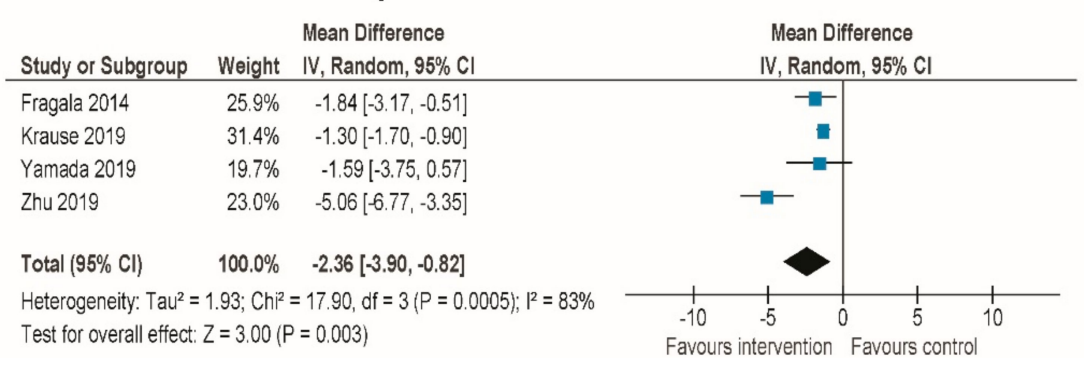

Figure 6. Effects of whole-body vibration and resistance exercise on functional mobility tests.

\section{Discussion}

The purpose of this systematic review with meta-analysis was to investigate the effects of RT, WBV, and EMS interventions on muscle strength, body composition, and functional performance in older 
adults. It included randomized controlled trials involving at least one intervention group (RT, EMS, or WBV) and a control group were included. In total, 64 studies were included in the meta-analysis (48 RT studies, 12 WBV studies, and 4 EMS studies). The main findings of the present systematic reviews are: (1) knee extension strength was improved by RT and WBV, but not ES; (2) the remaining strength outcomes were only assessed in RT studies and significant positive effects were observed; (3) the effects of RT on body composition were small, while the effects of WBV and EMS are unclear due to the small number of studies; (4) there were small effects on sarcopenia index, while quadriceps cross-sectional area was improved in RT studies, but not WBV studies; (5) functional performance was improved by RT interventions, though not in all tests. Overall, the RT interventions proved to be effective for improving muscle strength, muscle cross-sectional area and functional performance, while the effects on body composition were small or non-existent. WBV seems to be comparably effective for improving muscle strength, but not muscle cross-sectional area. A major limitation of the review is the smaller number of WBV and particularly EMS studies. Comparisons between the different intervention types were therefore limited and were not possible for several outcome measures. Subgroup analyses revealed that some of the independent variables (duration of intervention, weekly frequency, type of resistance in RT studies, and age of participants) might have influenced the results; however, these findings were not statistically significant and cannot be conclusively confirmed.

The positive effects of RT, WBV, and EMS in older adults have been reported numerous times [9-11,13,14,19,22,23,25,26,30,31,91-93]. In this review, we included only randomized controlled trials that included at least one group that did not receive any interventions (control group). While the positive effects of RT were clearly demonstrated, the effects of WBV, and in particular EMS, were smaller or absent. Individual studies that directly compared RT and WBV have shown similar effects of the two interventions related to muscle strength and power outcomes [25,26]. In a non-controlled single-group study, improvements in muscle strength and power and functional performance were also observed after 9 weeks of WBV [94]. While the present review showed improvements in muscle strength after WBV interventions, only 2 WBV studies that assessed functional performance were included. Therefore, the effects of WBV on functional performance remain unclear. Since improvements in functional performance are often observed in parallel with increases in muscle strength $[92,95,96]$ and muscle power [97], it can be expected that WBV will also increase functional performance. In addition to increases on muscle strength and possible improvements in functional performance after WBV, previous research also showed positive effects of WBV on postural balance [22], cardiovascular outcomes [98] and possibly muscle activation [99] in older adults. Overall, we can recommend the prescription of WBV to older adults, but it cannot be guaranteed that WBV will produce comparable effects to RT in view of all outcomes relevant to health and well-being.

EMS has been used extensively in people who cannot engage in normal physical activity and has been shown to produce somewhat similar responses to exercise at the muscular level [100]. In this review, a very limited amount of randomized controlled trials has been identified to investigate the effects of EMS in older adults. Our analyses could not confirm or indicate any effects of EMS interventions. EMS has previously been shown to be effective in counteracting muscle weakness in advanced disease [101] and sarcopenia in older adults [30,32], and even to provide additive effects in terms of morphological outcomes when combined with RT in healthy adults [102]. However, the effect of EMS on functional performance of the older adults are less consistent [103]. Nevertheless, the above-mentioned promising results should be re-evaluated in randomized controlled trials to strengthen the findings and enable better comparison to RT and WBV. Based on the results of this and previous research [92], the use of EMS should be encouraged when performing physical activities is not possible or older adults are not motivated to perform it.

Across all interventions, the improvements in muscle strength were much more evident than improvements in muscle mass. It is known that improvements in strength due to neural adaptations occur much earlier before a meaningful increase in muscle mass is seen [104]. While most of the interventions in the present review lasted 12 weeks or longer, improvements in muscle mass could 
nonetheless be expected. It is possible that muscle mass measurements are not reliable enough to detect the effect of the interventions. Alternatively, the cross-sectional area of the quadriceps was statistically significantly increased across RT studies in this review. Moreover, a previous review also reported notable increases in the cross-sectional area of thigh muscles $\left(+2.31 \mathrm{~cm}^{2}\right)$ in older adults aged $>75$ years [105]. Interestingly, the latter review reported such effects for WBV, while the pooled effects of the WBV studies in our review were small.

The results on functional performance were different across outcome measures. Neither WBV, RT nor EMS improved the performance of the timed up-and-go test. Conversely, the sit-stand performance was significantly improved by RT interventions (an increase of 2.68 repetitions in 30-s sit-stand task and a decrease of $2.36 \mathrm{~s}$ in the 5-repetition sit-stand task time). It should be noted that the results regarding functional performance were significantly influenced by the heterogeneity of the studies. In particular, the timed up-and-go test performance was substantially improved $(-1.77 \mathrm{~s})$ in one study and reduced even more in the second study $(+1.99 \mathrm{~s})$. Similarly, most RT studies showed improvements in this test, but one study [69] showed a large reduction (+3.6 s), which led to a negligible pooled effect. This particular study was conducted on very old participants ( $>90$ years) and included a short-term resistance exercise program, based on light to moderate loads. If this study is excluded from the analysis, the pooled effect size would show statistically significant positive improvements $(\mathrm{MD}=-0.93 \mathrm{~s} ; p<0.001)$.

The secondary aim of this paper was to determine the independent variables, related to the interventions, that can influence the magnitude of the outcomes. Most of the subgroup analyses that could be conducted as the number of studies was sufficient, showed no such statistically significant effects. There were statistically non-significant trends for lower limb muscle mass and leg press strength to be improved more with a higher $(\geq 3)$ weekly session frequency. The literature in the field of sports science $[106,107]$ suggests that weekly frequency is not an independent factor for improvements in muscle strength and muscle mass. A recent meta-analysis suggested that similar is true for older adults [108], although a minimum of 2 sessions per week is typically recommended. Our results also indicated a potentially higher effect of interventions based on machine training and free weights, compared to elastic resistance and approaches combining several types of resistance. In the general population, the effect of elastic resistance appears to be essentially the same as machine-based resistance and free weights [109]. Note that our observation on lesser effects of elastic resistance compared to machines and free weights is limited to knee extension strength and that the difference between the effect of elastic resistance (SMD $=0.91)$ and machine-based resistance (SMD $=1.36$ ) and free weights (SMD $=1.33$ ) was not statistically significant $(p=0.68)$. Therefore, it is probably appropriate to include elastic resistance in RT programs for older adults.

The first limitation of this systematic review with meta-analysis is the inclusion of only randomized controlled trials. While this was done to compile only high-quality evidence, important findings from studies with different designs were omitted. In particular, the number of EMS studies was very small. It should be emphasized that the lack of reported effects of EMS in the review is partly due to the lack of randomized controlled trials and not necessarily because the EMS is not effective. Furthermore, a major limitation of the review is the high heterogeneity of the studies, which precluded more subgroup analyses and is potentially a major confounding factor. Partially, we investigated this issue with several sensitivity analyses which showed that the results were not heavily influenced by certain factors, such as type of measurements (for knee strength), presence of sarcopenia (though somewhat smaller effects were observed in elderly sarcopenia patients), and adherence to studies. Because there are several factors that can influence response to resistance exercise (in particular, the characteristics of the intervention in addition to those mentioned above), we did our best to perform subgroup analyses to exclude or confirm several factors, such as exercise frequency, intervention duration, and resistance exercise type. Nevertheless, some of the variability between the interventions could not be accounted for. Therefore, we strongly emphasize that these results should be viewed with high caution. Future 
studies and practitioners should not use the numbers we obtained as a standalone guideline, but rather view our analyses as an exploration of general trends in the field of interventions for older adults.

\section{Conclusions}

This paper reviewed RCT studies that examined the effects of RT, WBV, and EMS on muscle strength, body composition, and functional performance of older adults. It was found that RT and WBV are effective for increasing muscle strength, while the data was very limited for EMS. RT interventions also improve functional performance and increase muscle-cross sectional area but have no effect on muscle mass. Further studies exploring the effect of WBV and in particular of EMS are needed for better comparison with RT. For the time being, EMS can be recommended for people that are unable to perform RT or WBV. Otherwise, RT or a combination of RT and WBV or EMS is probably the most efficient way to improve muscle strength and functional performance, while the best approach to increase muscle mass in older adults still needs to be determined by further studies. Due to the several limitations of this review, we urge the readers to view the results with caution.

Supplementary Materials: The following are available online at http://www.mdpi.com/2077-0383/9/9/2902/s1, Supplementary data 1: Detailed data regarding study outcomes, interventions and participants.

Author Contributions: Conceptualization, N.S. and Ž.K.; methodology, N.Š., Ž.K., S.L., C.H.; software, Ž.K.; formal analysis, N.Š., Ž.K., S.L., C.H.; investigation, N.Š., Ž.K., S.L., C.H.; resources, N.S., S.L.; data curation, N.Š., Ž.K., S.L., C.H.; writing—original draft preparation, N.Š., Ž.K.; writing-review and editing, S.L., C.H.; visualization, N.Š, Ž.K.; supervision, N.S.; project administration, N.Š. funding acquisition, S.L. All authors have read and agreed to the published version of the manuscript.

Funding: The study was supported by Institute for Physical Medicine and Rehabilitation, Physiko- \& Rheumatherapie GmbH.

Acknowledgments: We want to acknowledge the support of the European Regional Development Fund and Physiko- and Rheumatherapie institute through the Centre of Active Ageing project in the Interreg Slovakia-Austria cross-border cooperation program (partners: Faculty for Physical Education and Sports, Comenius University in Bratislava: Institute for Physical Medicine and Rehabilitation, Physiko- \& Rheumatherapie $\mathrm{GmbH})$. Authors NS and ZK acknowledge the European Commission for funding the InnoRenew CoE project (Grant Agreement 739574) under the Horizon2020 Widespread-Teaming program.

Conflicts of Interest: The authors declare no conflict of interest.

\section{References}

1. Cheng, X.; Yang, Y.; Schwebel, D.C.; Liu, Z.; Li, L.; Cheng, P.; Ning, P.; Hu, G. Population ageing and mortality during 1990-2017: A global decomposition analysis. PLoS Med. 2020, 17, e1003138. [CrossRef] [PubMed]

2. Lutz, W.; Sanderson, W.; Scherbov, S. The coming acceleration of global population ageing. Nature 2008, 451, 716-719. [CrossRef] [PubMed]

3. Galloza, J.; Castillo, B.; Micheo, W. Benefits of Exercise in the Older Population. Phys. Med. Rehabil. Clin. N. Am. 2017, 28, 659-669. [CrossRef] [PubMed]

4. De Labra, C.; Guimaraes-Pinheiro, C.; Maseda, A.; Lorenzo, T.; Millán-Calenti, J.C. Effects of physical exercise interventions in frail older adults: A systematic review of randomized controlled trials. BMC Geriatr. 2015, 15, 154. [CrossRef] [PubMed]

5. Lopez, P.; Pinto, R.S.; Radaelli, R.; Rech, A.; Grazioli, R.; Izquierdo, M.; Cadore, E.L. Benefits of resistance training in physically frail elderly: A systematic review. Aging Clin. Exp. Res. 2018, 30, 889-899. [CrossRef] [PubMed]

6. Barreto, P.D.S.; Rolland, Y.; Vellas, B.; Maltais, M. Association of Long-term Exercise Training with Risk of Falls, Fractures, Hospitalizations, and Mortality in Older Adults: A Systematic Review and Meta-analysis. JAMA Intern. Med. 2019, 179, 394-405. [CrossRef]

7. Cvecka, J.; Tirpakova, V.; Sedliak, M.; Kern, H.; Mayr, W.; Hamar, D. Physical activity in elderly. Eur. J. Transl. Myol. 2015, 25, 249-252. [CrossRef] 
8. Cruz-Jentoft, A.J.; Bahat, G.; Bauer, J.; Boirie, Y.; Bruyère, O.; Cederholm, T.; Cooper, C.; Landi, F.; Rolland, Y.; Sayer, A.A.; et al. Sarcopenia: Revised European consensus on definition and diagnosis. Age Ageing 2019, 48, 16-31. [CrossRef]

9. Phu, S.; Boersma, D.; Duque, G. Exercise and Sarcopenia. J. Clin. Densitom. 2015, 18, 488-492. [CrossRef]

10. Landi, F.; Marzetti, E.; Martone, A.M.; Bernabei, R.; Onder, G. Exercise as a remedy for sarcopenia. Curr. Opin. Clin. Nutr. Metab. Care 2014, 17, 25-31. [CrossRef]

11. Marzetti, E.; Calvani, R.; Tosato, M.; Cesari, M.; Di Bari, M.; Cherubini, A.; Broccatelli, M.; Savera, G.; D'Elia, M.; Pahor, M.; et al. Physical activity and exercise as countermeasures to physical frailty and sarcopenia. Aging Clin. Exp. Res. 2017, 29, 35-42. [CrossRef] [PubMed]

12. Cuevas-Trisan, R. Balance Problems and Fall Risks in the Elderly. Phys. Med. Rehabil. Clin. N. Am. 2017, 28, 727-737. [CrossRef] [PubMed]

13. Tricco, A.C.; Thomas, S.M.; Veroniki, A.A.; Hamid, J.S.; Cogo, E.; Strifler, L.; Khan, P.A.; Robson, R.; Sibley, K.M.; MacDonald, H.; et al. Comparisons of interventions for preventing falls in older adults: A systematic review and meta-analysis. JAMA J. Am. Med. Assoc. 2017, 318, 1687-1699. [CrossRef] [PubMed]

14. Sherrington, C.; Michaleff, Z.A.; Fairhall, N.; Paul, S.S.; Tiedemann, A.; Whitney, J.; Cumming, R.G.; Herbert, R.D.; Close, J.C.T.; Lord, S.R. Exercise to prevent falls in older adults: An updated systematic review and meta-analysis. Br. J. Sports Med. 2017, 51, 1749-1757. [CrossRef]

15. Aguirre, L.E.; Villareal, D.T. Physical Exercise as Therapy for Frailty. Nestle Nutr. Inst. Workshop Ser. 2015, 83, 83-92. [CrossRef]

16. Csapo, R.; Alegre, L.M. Effects of resistance training with moderate vs heavy loads on muscle mass and strength in the elderly: A meta-analysis. Scand. J. Med. Sci. Sports 2016, 26, 995-1006. [CrossRef]

17. Watanabe, Y.; Tanimoto, M.; Oba, N.; Sanada, K.; Miyachi, M.; Ishii, N. Effect of resistance training using bodyweight in the elderly: Comparison of resistance exercise movement between slow and normal speed movement. Geriatr. Gerontol. Int. 2015, 15, 1270-1277. [CrossRef]

18. Lacroix, A.; Hortobágyi, T.; Beurskens, R.; Granacher, U. Effects of Supervised vs. Unsupervised Training Programs on Balance and Muscle Strength in Older Adults: A Systematic Review and Meta-Analysis. Sports Med. 2017, 47, 2341-2361. [CrossRef]

19. Šarabon, N.; Smajla, D.; Kozinc, Ž.; Kern, H. Speed-power based training in the elderly and its potential for daily movement function enhancement. Eur. J. Transl. Myol. 2020, 30, 8898. [CrossRef]

20. Yarmohammadi, S.; Saadati, H.M.; Ghaffari, M.; Ramezankhani, A. A systematic review of barriers and motivators to physical activity in elderly adults in Iran and worldwide. Epidemiol. Health 2019, 41, e2019049. [CrossRef]

21. Freiberger, E.; Kemmler, W.; Siegrist, M.; Sieber, C. Frailty und Trainingsinterventionen: Evidenz und Barrieren für Bewegungsprogramme. Z. Gerontol. Geriatr. 2016, 49, 606-611. [CrossRef] [PubMed]

22. Rogan, S.; Taeymans, J.; Radlinger, L.; Naepflin, S.; Ruppen, S.; Bruelhart, Y.; Hilfiker, R. Effects of whole-body vibration on postural control in elderly: An update of a systematic review and meta-analysis. Arch. Gerontol. Geriatr. 2017, 73, 95-112. [CrossRef] [PubMed]

23. Rogan, S.; de Bruin, E.D.; Radlinger, L.; Joehr, C.; Wyss, C.; Stuck, N.J.; Bruelhart, Y.; de Bie, R.A.; Hilfiker, R. Effects of whole-body vibration on proxies of muscle strength in old adults: A systematic review and meta-analysis on the role of physical capacity level. Eur. Rev. Aging Phys. Act. 2015, 12, 12. [CrossRef] [PubMed]

24. Jepsen, D.B.; Thomsen, K.; Hansen, S.; Jørgensen, N.R.; Masud, T.; Ryg, J. Effect of whole-body vibration exercise in preventing falls and fractures: A systematic review and meta-analysis. BMJ Open 2017, 7, e018342. [CrossRef]

25. Roelants, M.; Delecluse, C.; Verschueren, S.M. Whole-body-vibration training increases knee-extension strength and speed of movement in older women. J. Am. Geriatr. Soc. 2004, 52, 901-908. [CrossRef]

26. Bogaerts, A.; Delecluse, C.; Claessens, A.; Coudyzer, W.; Boonen, S.; Verschueren, S. Impact of Whole-Body Vibration Training Versus Fitness Training on Muscle Strength and Muscle Mass in Older Men: A 1-Year Randomized Controlled Trial. J. Gerontol. Ser. A 2007, 62, 630-635. [CrossRef]

27. Mayr, W. Neuromuscular electrical stimulation for mobility support of elderly. Eur. J. Transl. Myol. 2015, 25, 263-268. [CrossRef]

28. Pette, D.; Vrbová, G. The contribution of neuromuscular stimulation in elucidating muscle plasticity revisited. Eur. J. Transl. Myol. 2017, 27, 33-39. [CrossRef] 
29. Taylor, M.J.; Schils, S.; Ruys, A.J. Home FES: An exploratory review. Eur. J. Transl. Myol. 2019, $29,283-292$. [CrossRef]

30. Kern, H.; Barberi, L.; Löfler, S.; Sbardella, S.; Burggraf, S.; Fruhmann, H.; Carraro, U.; Mosole, S.; Sarabon, N.; Vogelauer, M.; et al. Electrical stimulation (ES) counteracts muscle decline in seniors. Front. Aging Neurosci. 2014, 6. [CrossRef]

31. Zampieri, S.; Mosole, S.; Löfler, S.; Fruhmann, H.; Burggraf, S.; Cvečka, J.; Hamar, D.; Sedliak, M.; Tirptakova, V.; Šarabon, N.; et al. Physical exercise in Aging: Nine weeks of leg press or electrical stimulation training in 70 years old sedentary elderly people. Eur. J. Transl. Myol. 2015, 25, 237-242. [CrossRef] [PubMed]

32. O'Connor, D.; Brennan, L.; Caulfield, B. The use of neuromuscular electrical stimulation (NMES) for managing the complications of ageing related to reduced exercise participation. Maturitas 2018, 113, 13-20. [CrossRef] [PubMed]

33. Methley, A.M.; Campbell, S.; Chew-Graham, C.; McNally, R.; Cheraghi-Sohi, S. PICO, PICOS and SPIDER: A comparison study of specificity and sensitivity in three search tools for qualitative systematic reviews. BMC Health Serv. Res. 2014, 14, 579. [CrossRef] [PubMed]

34. Maher, C.G.; Sherrington, C.; Herbert, R.D.; Moseley, A.M.; Elkins, M. Reliability of the PEDro Scale for Rating Quality of Randomized Controlled Trials. Phys. Ther. 2003, 83, 713-721. [CrossRef]

35. Higgins, J.P.T.; Green, S. Cochrane Handbook for Systematic Reviews of Interventions|Cochrane Training. Available online: https://raining.cochrane.org/handbook/current (accessed on 15 May 2020).

36. Kemmler, W.; von Stengel, S. Whole-body electromyostimulation as a means to impact muscle mass and abdominal body fat in lean, sedentary, older female adults: Subanalysis of the TEST-III trial. Clin. Interv. Aging 2013, 8, 1353-1364. [CrossRef]

37. Bezerra, P.; Zhou, S.; Crowley, Z.; Davie, A.; Baglin, R. Effects of electromyostimulation on knee extensors and flexors strength and steadiness in older adults. J. Mot. Behav. 2011, 43, 413-421. [CrossRef]

38. Bogaerts, A.C.; Delecluse, C.; Claessens, A.L.; Troosters, T.; Boonen, S.; Verschueren, S.M. Effects of whole body vibration training on cardiorespiratory fitness and muscle strength in older individuals (a 1-year randomised controlled trial). Age Ageing 2009, 38. [CrossRef]

39. Marín-Cascales, E.; Rubio-Arias, J.A.; Romero-Arenas, S.; Alcaraz, P.E. Effect of 12 weeks of whole-body vibration versus multi-component training in post-menopausal women. Rejuvenation Res. 2015, 18, 508-516. [CrossRef]

40. Verschueren, S.M.; Bogaerts, A.; Delecluse, C.; Claessens, A.L.; Haentjens, P.; Vanderschueren, D.; Boonen, S. The effects of whole-body vibration training and vitamin D supplementation on muscle strength, muscle mass, and bone density in institutionalized elderly women: A 6-month randomized, controlled trial. J. Bone Miner. Res. 2011, 26, 42-49. [CrossRef]

41. Zheng, A.; Sakari, R.; Cheng, S.M.; Hietikko, A.; Moilanen, P.; Timonen, J.; Fagerlund, K.M.; Kärkkäinen, M.; Alèn, M.; Cheng, S. Effects of a low-frequency sound wave therapy programme on functional capacity, blood circulation and bone metabolism in frail old men and women. Clin. Rehabil. 2009, 23, 897-908. [CrossRef]

42. Wei, N.; Pang, M.Y.C.; Ng, S.S.M.; Ng, G.Y.F. Optimal frequency/time combination of whole-body vibration training for improving muscle size and strength of people with age-related muscle loss (sarcopenia): A randomized controlled trial. Geriatr. Gerontol. Int. 2017, 17, 1412-1420. [CrossRef] [PubMed]

43. Bunout, D.; Barrera, G.; de la Maza, P.; Avendaño, M.; Gattas, V.; Petermann, M.; Hirsch, S. The impact of nutritional supplementation and resistance training on the health functioning of free-living Chilean elders: Results of 18 months of follow-up. J. Nutr. 2001, 131, 2441S-2446S. [CrossRef] [PubMed]

44. Iranzo, M.A.C.; Balasch-Bernat, M.; Tortosa-Chuliá, M.; Balasch-Parisi, S. Effects of resistance training of peripheral muscles versus respiratory muscles in older adults with sarcopenia who are institutionalized: A randomized controlled trial. J. Aging Phys. Act. 2018, 26, 637-646. [CrossRef] [PubMed]

45. Chen, H.T.; Chung, Y.C.; Chen, Y.J.; Ho, S.Y.; Wu, H.J. Effects of Different Types of Exercise on Body Composition, Muscle Strength, and IGF-1 in the Elderly with Sarcopenic Obesity. J. Am. Geriatr. Soc. 2017, 65, 827-832. [CrossRef] [PubMed]

46. De Vos, N.J.; Singh, N.A.; Ross, D.A.; Stavrinos, T.M.; Orr, R.; Singh, M.A.F. Optimal load for increasing muscle power during explosive resistance training in older adults. J. Gerontol. Ser. A 2005, 60, 638-647. [CrossRef] [PubMed]

47. Frontera, W.R.; Hughes, V.A.; Krivickas, L.S.; Kim, S.K.; Foldvari, M.; Roubenoff, R. Strength training in older women: Early and late changes in whole muscle and single cells. Muscle Nerve 2003, 28, 601-608. [CrossRef] 
48. Giné-Garriga, M.; Guerra, M.; Pagès, E.; Manini, T.M.; Jiménez, R.; Unnithan, V.B. The effect of functional circuit training on physical frailty in frail older adults: A randomized controlled trial. J. Aging Phys. Act. 2010, 18, 401-424. [CrossRef]

49. Ikezoe, T.; Tsutou, A.; Asakawa, Y.; Tsuboyama, T. Low Intensity Training for Frail Elderly Women: Long-term Effects on Motor Function and Mobility. J. Phys. Ther. Sci. 2005, 17, 43-49. [CrossRef]

50. Jung, W.S.; Kim, Y.Y.; Park, H.Y. Circuit Training Improvements in Korean Women with Sarcopenia. Percept. Mot. Skills 2019, 126, 828-842. [CrossRef]

51. Kim, H.K.; Suzuki, T.; Saito, K.; Yoshida, H.; Kobayashi, H.; Kato, H.; Katayama, M. Effects of exercise and amino acid supplementation on body composition and physical function in community-dwelling elderly Japanese sarcopenic women: A randomized controlled trial. J. Am. Geriatr. Soc. 2012, 60, 16-23. [CrossRef]

52. Kim, H.; Suzuki, T.; Saito, K.; Yoshida, H.; Kojima, N.; Kim, M.; Sudo, M.; Yamashiro, Y.; Tokimitsu, I. Effects of exercise and tea catechins on muscle mass, strength and walking ability in community-dwelling elderly Japanese sarcopenic women: A randomized controlled trial. Geriatr. Gerontol. Int. 2013, 13, 458-465. [CrossRef]

53. Kim, H.; Kim, M.; Kojima, N.; Fujino, K.; Hosoi, E.; Kobayashi, H.; Somekawa, S.; Niki, Y.; Yamashiro, Y.; Yoshida, H. Exercise and Nutritional Supplementation on Community-Dwelling Elderly Japanese Women With Sarcopenic Obesity: A Randomized Controlled Trial. J. Am. Med. Dir. Assoc. 2016, 17, 1011-1019. [CrossRef] [PubMed]

54. Kryger, A.I.; Andersen, J.L. Resistance training in the oldest old: Consequences for muscle strength, fiber types, fiber size, and MHC isoforms. Scand. J. Med. Sci. Sports 2007, 17, 422-430. [CrossRef] [PubMed]

55. De Liao, C.; Tsauo, J.Y.; Lin, L.F.; Huang, S.W.; Ku, J.W.; Chou, L.C.; Liou, T.H. Effects of elastic resistance exercise on body composition and physical capacity in older women with sarcopenic obesity. Medicine 2017, 96, e7115. [CrossRef]

56. Martins, W.R.; Safons, M.P.; Bottaro, M.; Blasczyk, J.C.; Diniz, L.R.; Fonseca, R.M.C.; Bonini-Rocha, A.C.; De Oliveira, R.J. Effects of short term elastic resistance training on muscle mass and strength in untrained older adults: A randomized clinical trial. BMC Geriatr. 2015, 15, 99. [CrossRef]

57. Matsufuji, S.; Shoji, T.; Yano, Y.; Tsujimoto, Y.; Kishimoto, H.; Tabata, T.; Emoto, M.; Inaba, M. Effect of Chair Stand Exercise on Activity of Daily Living: A Randomized Controlled Trial in Hemodialysis Patients. J. Ren. Nutr. 2015, 25, 17-24. [CrossRef] [PubMed]

58. Mueller, M.; Breil, F.A.; Vogt, M.; Steiner, R.; Klossner, S.; Hoppeler, H.; Däpp, C.; Lippuner, K.; Popp, A. Different response to eccentric and concentric training in older men and women. Eur. J. Appl. Physiol. 2009, 107, 145-153. [CrossRef]

59. Oesen, S.; Halper, B.; Hofmann, M.; Jandrasits, W.; Franzke, B.; Strasser, E.M.; Graf, A.; Tschan, H.; Bachl, N.; Quittan, M.; et al. Effects of elastic band resistance training and nutritional supplementation on physical performance of institutionalised elderly-A randomized controlled trial. Exp. Gerontol. 2015, 72, 99-108. [CrossRef]

60. Reid, K.F.; Callahan, D.M.; Carabello, R.J.; Phillips, E.M.; Frontera, W.R.; Fielding, R.A. Lower extremity power training in elderly subjects with mobility limitations: A randomized controlled trial. Aging Clin. Exp. Res. 2008, 20, 337-343. [CrossRef]

61. Rhodes, E.C.; Martin, A.D.; Taunton, J.E.; Donnelly, M.; Warren, J.; Elliot, J. Effects of one year of resistance training on the relation between muscular strength and bone density in elderly women. Br. J. Sports Med. 2000, 34, 18-22. [CrossRef]

62. Scanlon, T.C.; Fragala, M.S.; Stout, J.R.; Emerson, N.S.; Beyer, K.S.; Oliveira, L.P.; Hoffman, J.R. Muscle architecture and strength: Adaptations to short-term resistance training in older adults. Muscle Nerve 2014, 49, 584-592. [CrossRef]

63. Su, Z.; Zhao, J.; Wang, N.; Chen, Y.; Guo, Y.; Tian, Y. Effects of weighted tai chi on leg strength of older adults. J. Am. Geriatr. Soc. 2015, 63, 2208-2210. [CrossRef] [PubMed]

64. Vasconcelos, K.S.S.; Dias, J.M.D.; Araújo, M.C.; Pinheiro, A.C.; Moreira, B.S.; Dias, R.C. Effects of a progressive resistance exercise program with high-speed component on the physical function of older women with sarcopenic obesity: A randomized controlled trial. Brazilian J. Phys. Ther. 2016, 20, 432-440. [CrossRef]

65. Yamada, M.; Kimura, Y.; Ishiyama, D.; Nishio, N.; Otobe, Y.; Tanaka, T.; Ohji, S.; Koyama, S.; Sato, A.; Suzuki, M.; et al. Synergistic effect of bodyweight resistance exercise and protein supplementation on 
skeletal muscle in sarcopenic or dynapenic older adults. Geriatr. Gerontol. Int. 2019, 19, 429-437. [CrossRef] [PubMed]

66. Yoon, S.J.; Lee, M.J.; Lee, H.M.; Lee, J.S. Effect of low-intensity resistance training with heat stress on the HSP72, anabolic hormones, muscle size, and strength in elderly women. Aging Clin. Exp. Res. 2017, 29, 977-984. [CrossRef] [PubMed]

67. Zhu, L.Y.; Chan, R.; Kwok, T.; Cheng, K.C.C.; Ha, A.; Woo, J. Effects of exercise and nutrition supplementation in community-dwelling older Chinese people with sarcopenia: A randomized controlled trial. Age Ageing 2019, 48, 220-228. [CrossRef] [PubMed]

68. Gualano, B.; Macedo, A.R.; Alves, C.R.R.; Roschel, H.; Benatti, F.B.; Takayama, L.; de Sá Pinto, A.L.; Lima, F.R.; Pereira, R.M.R. Creatine supplementation and resistance training in vulnerable older women: A randomized double-blind placebo-controlled clinical trial. Exp. Gerontol. 2014, 53, 7-15. [CrossRef]

69. Serra-Rexach, J.A.; Bustamante-Ara, N.; Hierro Villarán, M.; González Gil, P.; Sanz Ibáñez, M.J.; Blanco Sanz, N.; Ortega Santamaría, V.; Gutiérrez Sanz, N.; Marín Prada, A.B.; Gallardo, C.; et al. Short-term, light- to moderate-intensity exercise training improves leg muscle strength in the oldest old: A randomized controlled trial. J. Am. Geriatr. Soc. 2011, 59, 594-602. [CrossRef]

70. Chen, H.T.; Wu, H.J.; Chen, Y.J.; Ho, S.Y.; Chung, Y.C. Effects of 8-week kettlebell training on body composition, muscle strength, pulmonary function, and chronic low-grade inflammation in elderly women with sarcopenia. Exp. Gerontol. 2018, 112, 112-118. [CrossRef]

71. Cunha, P.M.; Ribeiro, A.S.; Tomeleri, C.M.; Schoenfeld, B.J.; Silva, A.M.; Souza, M.F.; Nascimento, M.A.; Sardinha, L.B.; Cyrino, E.S. The effects of resistance training volume on osteosarcopenic obesity in older women. J. Sports Sci. 2018, 36, 1564-1571. [CrossRef]

72. DeBeliso, M.; Harris, C.; Spitzer-Gibson, T.; Adams, K.J. A comparison of periodised and fixed repetition training protocol on strength in older adults. J. Sci. Med. Sport 2005, 8, 190-199. [CrossRef]

73. Villareal, D.T.; Aguirre, L.; Gurney, A.B.; Waters, D.L.; Sinacore, D.R.; Colombo, E.; Armamento-Villareal, R.; Qualls, C. Aerobic or Resistance Exercise, or Both, in Dieting Obese Older Adults. N. Engl. J. Med. 2017, 376, 1943-1955. [CrossRef] [PubMed]

74. Dong, Z.J.; Zhang, H.L.; Yin, L.X. Effects of intradialytic resistance exercise on systemic inflammation in maintenance hemodialysis patients with sarcopenia: A randomized controlled trial. Int. Urol. Nephrol. 2019, 51, 1415-1424. [CrossRef] [PubMed]

75. Fragala, M.S.; Fukuda, D.H.; Stout, J.R.; Townsend, J.R.; Emerson, N.S.; Boone, C.H.; Beyer, K.S.; Oliveira, L.P.; Hoffman, J.R. Muscle quality index improves with resistance exercise training in older adults. Exp. Gerontol. 2014, 53, 1-6. [CrossRef] [PubMed]

76. Krause, M.; Crognale, D.; Cogan, K.; Contarelli, S.; Egan, B.; Newsholme, P.; De Vito, G. The effects of a combined bodyweight-based and elastic bands resistance training, with or without protein supplementation, on muscle mass, signaling and heat shock response in healthy older people. Exp. Gerontol. 2019, 115, 104-113. [CrossRef] [PubMed]

77. Lichtenberg, T.; Von Stengel, S.; Sieber, C.; Kemmler, W. The favorable effects of a high-intensity resistance training on sarcopenia in older community-dwelling men with osteosarcopenia: The randomized controlled frost study. Clin. Interv. Aging 2019, 14, 2173-2186. [CrossRef]

78. Piastra, G.; Perasso, L.; Lucarini, S.; Monacelli, F.; Bisio, A.; Ferrando, V.; Gallamini, M.; Faelli, E.; Ruggeri, P. Effects of Two Types of 9-Month Adapted Physical Activity Program on Muscle Mass, Muscle Strength, and Balance in Moderate Sarcopenic Older Women. BioMed Res. Int. 2018, 2018, 5095673. [CrossRef]

79. Tsuzuku, S.; Kajioka, T.; Sakakibara, H.; Shimaoka, K. Slow movement resistance training using body weight improves muscle mass in the elderly: A randomized controlled trial. Scand. J. Med. Sci. Sports 2018, 28, 1339-1344. [CrossRef]

80. Hong, J.; Kim, J.; Kim, S.W.; Kong, H.J. Effects of home-based tele-exercise on sarcopenia among community-dwelling elderly adults: Body composition and functional fitness. Exp. Gerontol. 2017, 87, 33-39. [CrossRef]

81. Huang, S.W.; Ku, J.W.; Lin, L.F.; Liao, C.D.; Chou, L.C.; Liou, T.H. Body composition influenced by progressive elastic band resistance exercise of sarcopenic obesity elderly women: A pilot randomized controlled trial. Eur. J. Phys. Rehabil. Med. 2017, 53, 556-563. [CrossRef]

82. Strasser, E.M.; Hofmann, M.; Franzke, B.; Schober-Halper, B.; Oesen, S.; Jandrasits, W.; Graf, A.; Praschak, M.; Horvath-Mechtler, B.; Krammer, C.; et al. Strength training increases skeletal muscle quality but not muscle 
mass in old institutionalized adults: A randomized, multi-arm parallel and controlled intervention study. Eur. J. Phys. Rehabil. Med. 2018, 54, 921-933. [CrossRef] [PubMed]

83. Gómez-Cabello, A.; González-Agüero, A.; Ara, I.; Casajús, J.A.; Vicente-Rodríguez, G. Efectos de una intervención de vibración corporal total sobre la masa magra en personas ancianas. Nutr. Hosp. 2013, 28, 1255-1258. [CrossRef] [PubMed]

84. Kemmler, W.; Bebenek, M.; Engelke, K.; Von Stengel, S. Impact of whole-body electromyostimulation on body composition in elderly women at risk for sarcopenia: The Training and ElectroStimulation Trial (TEST-III). Age (Omaha) 2014, 36, 395-406. [CrossRef] [PubMed]

85. Sousa, N.; Mendes, R.; Abrantes, C.; Sampaio, J.; Oliveira, J. Is once-weekly resistance training enough to prevent sarcopenia? J. Am. Geriatr. Soc. 2013, 61, 1423-1424. [CrossRef]

86. Kemmler, W.; Teschler, M.; Weissenfels, A.; Bebenek, M.; von Stengel, S.; Kohl, M.; Freiberger, E.; Goisser, S.; Jakob, F.; Sieber, C.; et al. Whole-body electromyostimulation to fight sarcopenic obesity in community-dwelling older women at risk. Resultsof the randomized controlled FORMOsA-sarcopenic obesity study. Osteoporos. Int. 2016, 27, 3261-3270. [CrossRef] [PubMed]

87. Machado, A.; García-López, D.; González-Gallego, J.; Garatachea, N. Whole-body vibration training increases muscle strength and mass in older women: A randomized-controlled trial. Scand. J. Med. Sci. Sports 2010, 20, 200-207. [CrossRef]

88. Santin-Medeiros, F.; Rey-López, J.P.; Santos-Lozano, A.; Cristi-Montero, C.S.; Vallejo, N.G. Effects of Eight Months of Whole-Body Vibration Training on the Muscle Mass and Functional Capacity of Elderly Women. J. Strength Cond. Res. 2015, 29, 1863-1869. [CrossRef]

89. Strandberg, E.; Ponsot, E.; Piehl-Aulin, K.; Falk, G.; Kadi, F. Resistance training alone or combined with N-3 PUFA-rich diet in older women: Effects on muscle Fiber hypertrophy. J. Gerontol. Ser. A 2019, 74, 489-494. [CrossRef]

90. Yu, W.; An, C.; Kang, H. Effects of resistance exercise using Thera-band on balance of elderly adults: A randomized controlled trial. J. Phys. Ther. Sci. 2013, 25, 1471-1473. [CrossRef]

91. Carraro, U.; Gava, K.; Baba, A.; Marcante, A.; Piccione, F. To contrast and reverse skeletal muscle atrophy by full-body in-bed gym, a mandatory lifestyle for older olds and borderline mobility-impaired persons. In Advances in Experimental Medicine and Biology; Springer: New York, NY, USA, 2018; Volume 1088, pp. 549-560.

92. Sajer, S.; Guardiero, G.S.; Scicchitano, B.M. Myokines in home-based functional electrical stimulation-induced recovery of skeletal muscle in elderly and permanent denervation. Eur. J. Transl. Myol. 2018, 28, 337-345. [CrossRef]

93. Oreská, L.; Slobodová, L.; Vajda, M.; Kaplánová, A.; Tirpáková, V.; Cvečka, J.; Buzgó, G.; Ukropec, J.; Ukropcová, B.; Sedliak, M. The effectiveness of two different multimodal training modes on physical performance in elderly. Eur. J. Transl. Myol. 2020, 30, 8920. [CrossRef]

94. Cristi, C.; Collado, P.S.; Márquez, S.; Garatachea, N.; Cuevas, M.J. Whole-body vibration training increases physical fitness measures without alteration of inflammatory markers in older adults. Eur. J. Sport Sci. 2014, 14, 611-619. [CrossRef] [PubMed]

95. Mazini Filho, M.L.; Aidar, F.J.; Gama De Matos, D.; Costa Moreira, O.; Patrocínio De Oliveira, C.E.; Rezende De Oliveira Venturini, G.; Magalhäes Curty, V.; Menezes Touguinha, H.; Caputo Ferreira, M.E. Circuit strength training improves muscle strength, functional performance and anthropometric indicators in sedentary elderly women. J. Sports Med. Phys. Fitness 2018, 58, 1029-1036. [CrossRef] [PubMed]

96. Lima, A.B.; de Souza Bezerra, E.; da Rosa Orssatto, L.B.; de Paiva Vieira, E.; Picanço, L.A.A.; dos Santos, J.O.L. Functional resistance training can increase strength, knee torque ratio, and functional performance in elderly women. J. Exerc. Rehabil. 2018, 14, 654-659. [CrossRef]

97. Bean, J.F.; Kiely, D.K.; Larose, S.; Goldstein, R.; Frontera, W.R.; Leveille, S.G. Are changes in leg power responsible for clinically meaningful improvements in mobility in older adults? J. Am. Geriatr. Soc. 2010, 58, 2363-2368. [CrossRef] [PubMed]

98. Licurci, M.D.; de Almeida Fagundes, A.; Arisawa, E.A. Acute effects of whole body vibration on heart rate variability in elderly people. J. Bodyw. Mov. Ther. 2018, 22, 618-621. [CrossRef]

99. Wei, N.; $\mathrm{Ng}$, G.Y.F. The effect of whole body vibration training on quadriceps voluntary activation level of people with age-related muscle loss (sarcopenia): A randomized pilot study. BMC Geriatr. 2018, 18, 240. [CrossRef] 
100. Barberi, L.; Scicchitano, B.M.; Musarò, A. Molecular and cellular mechanisms of muscle aging and sarcopenia and effects of electrical stimulation in seniors. Eur. J. Transl. Myol. 2015, 25, 231. [CrossRef]

101. Jones, S.; Man, W.D.C.; Gao, W.; Higginson, I.J.; Wilcock, A.; Maddocks, M. Neuromuscular electrical stimulation for muscle weakness in adults with advanced disease. Cochrane Database Syst. Rev. 2016, 2016, CD009419. [CrossRef]

102. Evangelista, A.; Teixeira, C.; Barros, B.M.; de Azevedo, J.; Paunksnis, M.; Souza, C.; Wadhi, T.; Rica, R.; Braz, T.V.; Bocalini, D. Does Whole-Body Electrical Muscle Stimulation Combined With Strength Training Promote Morphofunctional Alterations? Clinics 2019, 74, e1334. [CrossRef]

103. Langeard, A.; Bigot, L.; Chastan, N.; Gauthier, A. Does neuromuscular electrical stimulation training of the lower limb have functional effects on the elderly?: A systematic review. Exp. Gerontol. 2017, 91, 88-98. [CrossRef] [PubMed]

104. Hughes, D.C.; Ellefsen, S.; Baar, K. Adaptations to endurance and strength training. Cold Spring Harb. Perspect. Med. 2018, 8, a029769. [CrossRef] [PubMed]

105. Stewart, V.H.; Saunders, D.H.; Greig, C.A. Responsiveness of muscle size and strength to physical training in very elderly people: A systematic review. Scand. J. Med. Sci. Sports 2014, 24, e1-e10. [CrossRef] [PubMed]

106. Schoenfeld, B.J.; Ogborn, D.; Krieger, J.W. Effects of Resistance Training Frequency on Measures of Muscle Hypertrophy: A Systematic Review and Meta-Analysis. Sports Med. 2016, 46, 1689-1697. [CrossRef]

107. Ralston, G.W.; Kilgore, L.; Wyatt, F.B.; Buchan, D.; Baker, J.S. Weekly Training Frequency Effects on Strength Gain: A Meta-Analysis. Sports Med. Open 2018, 4, 36. [CrossRef]

108. Grgic, J.; Schoenfeld, B.J.; Davies, T.B.; Lazinica, B.; Krieger, J.W.; Pedisic, Z. Effect of Resistance Training Frequency on Gains in Muscular Strength: A Systematic Review and Meta-Analysis. Sports Med. 2018, 48, 1207-1220. [CrossRef]

109. Lopes, J.S.S.; Machado, A.F.; Micheletti, J.K.; de Almeida, A.C.; Cavina, A.P.; Pastre, C.M. Effects of training with elastic resistance versus conventional resistance on muscular strength: A systematic review and meta-analysis. SAGE Open Med. 2019, 7, 205031211983111. [CrossRef]

(C) 2020 by the authors. Licensee MDPI, Basel, Switzerland. This article is an open access article distributed under the terms and conditions of the Creative Commons Attribution (CC BY) license (http://creativecommons.org/licenses/by/4.0/). 